\title{
Famílias que maltratam: uma tentativa de socialização pela violência
}

\author{
Lidia Natalia Dobrianskeyj Weber ${ }^{1}$ \\ Ana Paula Viezzer \\ Olivia Justen Brandenburg \\ Claudia Regina Endo Zocche
}

\begin{abstract}
Resumo
Esta pesquisa teve como objetivo descrever o perfil das famílias envolvidas nas denúncias feitas ao programa SOS Criança de Curitiba entre os anos de 1995 e 2000. As pesquisadoras examinaram o conteúdo de 400 documentos, que continham o registro de crianças e adolescentes (entre 0 e 18 anos) vítimas de maus-tratos. A análise das denúncias comprovadas revelou que os vizinhos denunciaram mais freqüentemente (64,9\%). As denúncias envolveram 51,0\% de casos de agressão física, 34,4\% de negligência intrafamiliar, 7,3\% de abandono e 7,3\% de abuso sexual. Das vítimas, 48,5\% eram do sexo feminino e 51,5\% do sexo masculino. Dos agressores, $54,1 \%$ eram mães, $15,3 \%$ eram pais e $14,4 \%$ eram pais e mães. Os maus-tratos são um desrespeito contra as crianças e ferem seus direitos. Concluiu-se que a situação é de urgência, necessitando mais estudos científicos e medidas sociais mais eficazes.
\end{abstract}

Palavras-chave: Maus-tratos; Violência doméstica contra a criança; Agressão física.

\section{Abusive families: an attempt of socialization through the violence}

\begin{abstract}
The goal of the current study was to describe the profile of the families involved in complaints done to the SOS Criança of Curitiba from 1995 to 2000. The researchers examined the content of 400 documents, related to the record of the victimized children and adolescents (aged 0-18 years old). The analysis of the data (which delations were confirmed) revealed that most of the complaints $(64,9 \%)$ came from neighborhoods. The complaints involved $51,0 \%$ cases of physical aggression, $34,4 \%$ of neglect, $7,3 \%$ of abandon and $7,3 \%$ of sexual abuse. About the victims: $48,5 \%$ were girls and 51,5\% were boys. About the aggressors: $54,1 \%$ were mothers, $15,3 \%$ were fathers and $14,4 \%$ were both of them. Abuse is disrespect against children and their rights. Authors conclude that the situation is urgent, more scientific studies and more social attitudes are necessary.
\end{abstract}

Keywords: Child maltreatment; Domestic violence; Child abuse.

\section{Introdução}

Maus-tratos contra crianças e adolescentes na esfera doméstica fazem parte de um debate que inclui tanto a criança como sujeito de direitos, quanto as práticas educativas parentais e o compromisso da comunidade em relação à prevenção e identificação dos casos. Entende-se maus-tratos como negligência (abandono e o não-oferecimento de necessidades básicas da criança) ou abuso físico, emocional ou sexual. Considera-se que existe ocorrência de violência física quando uma criança ou adolescente foi vítima de danos ou correu risco de danos como resultado de ser agredida com a mão ou outro objeto, ou ser chutada, sacudida, jogada, queimada, ou golpeada pelos pais ou responsáveis. Diversos autores
(Newell, 1989; Straus, 1994; Hyman, 1997; Guerra, 1998; Azevedo \& Guerra, 2001; Weber, 2001) consideram que bater nos filhos insere-se num só continuum de violência que vai desde uma simples palmada até o espancamento. Negligência física refere-se a prejuízo ou risco como resultado de formas inadequadas de nutrição, vestimenta, higiene e supervisão. Abuso emocional inclui abuso verbal, punições não físicas inadequadas (por exemplo, ser amarrado) e ameaças de maus-tratos. Negligência emocional significa falha em prover suporte emocional adequado ou permitir que a criança presencie violência doméstica (Kaplan, 1999).

Os maus-tratos contra a criança existem desde a Antigüidade, em todas as classes sociais e nas mais diferentes culturas. Estudos históricos mostram que, até o

${ }^{1}$ Endereço para correspondência:

UFPR - Dep. de Psicologia - Praça Santos Andrade, 50/1 ${ }^{\circ}$ andar - Curitiba-PR - 80020-300

E-mail: lidiaw@uol.com.br ou http://sites.uol.com.br/lidiaw 
século XVII, as crianças não eram consideradas como seres com particularidades próprias e, portanto, a noção de maus-tratos à infância não era sequer considerada e, até o século XIX, não existiam sequer leis específicas para as crianças (Ariés, 1986; Badinter, 1985; Gallardo, 1988; McCaghy, 1985; Roig \& Ochotorena, 1993). A preocupação com a conceituação e compreensão dos maus-tratos contra a criança surge tardiamente na história da humanidade, na metade do século XIX, coincidindo com a polarização social em torno da família, como descreve Ariès (1986, p. 11): "A família tornou-se o lugar de uma afeição necessária entre os cônjuges e entre pais e filhos." Paralelamente, desde o século XVII ocorreu um movimento de mudança no nível dos costumes, que associava os conceitos de infância aos de inocência e fragilidade, contrariamente à noção partilhada por alguns teólogos, especialmente Santo Agostinho (354-430 d. C.), que justificava a violência física e o castigo corporal pelo argumento da corrupção moral da infância (Machado, 1996). No início da Renascença a preocupação era de que a criança, como toda criatura, era má e tudo levava ao mal. Ainda no início do século XX, as relações entre pais e filhos eram permeadas pela agressão.

Uma das maiores dificuldades tem sido a negação desse fenômeno. Nos últimos 150 anos, os maus-tratos na infância têm sido vistos como um problema social, com complexos mecanismos sociolegais que pretendem regulá-lo (Sibila, 2001), mas somente foi constituído como um problema social específico e autônomo em 1950, com a identificação da "síndrome da criança espancada". Embora a infância tenha adquirido maior importância nos aspectos sociais, jurídicos e familiares, essa condição continua convivendo, até os dias atuais, com a aceitação generalizada da punição física como uma prática educativa não apenas aceitável como recomendada. Se, até pouco tempo atrás, a família ainda era uma instituição imune a qualquer crítica externa, graças a sua lendária função de proteção e cuidado (Azevedo, 1990 citado por Guerra, 1994; Guerra, 1998; Veronese, 1998), o desrespeito aos direitos da criança e do adolescente ainda é evidente.

O Brasil apresenta graves deficiências em matéria de dados epidemiológicos (Oliveira \& Flores, 1999) e as políticas públicas parecem ainda não se ter sensibilizado com os maus-tratos à infância. No Brasil não existem estatísticas nacionais fidedignas sobre $\mathrm{o}$ tema, apenas registros esparsos de serviços isolados ou de pesquisadores, que não traduzem a realidade atual, dificultando um maior enfrentamento do problema. $\mathrm{O}$ fenômeno da violência doméstica contra crianças e adolescentes é muito mais freqüente do que se possa imaginar, e estima-se que apenas $20 \%$ dos casos de maus-tratos sejam denunciados. A notificação dos casos a órgãos competentes é uma prática pouco exercida pela comunidade e o pacto do silêncio paira trazendo danos à criança e sua família.

O SOS Criança é um programa da Prefeitura Municipal de Curitiba que visa à proteção integral a crianças e adolescentes vítimas de violência doméstica, como a agressão física e emocional, negligência, abandono e abuso sexual. Atua por meio de denúncias da comunidade e faz o diagnóstico, promoção, defesa e prevenção dos maus-tratos ocorridos dentro de casa contra crianças e adolescentes. O SOS Criança de Curitiba, mediante uma denúncia, averigua a situação, detecta o problema e elege uma solução entre as apresentadas no Estatuto da Criança e do Adolescente (ECA). Contudo, se o SOS Criança somente atender aos casos emergenciais, sem chegar às raízes do problema, as violações possivelmente continuarão, e em maior intensidade (Alberton, 1999). É necessário, então, o engajamento de toda a sociedade, e não somente de alguns profissionais que se dedicam ao tema, para a reivindicação de outros serviços ou programas, ou pelo menos, "a melhoria dos já existentes" (Caminha, 1999; Alberton, 1999), para que os dados coletados na presente pesquisa façam parte do passado.

Não fez parte do objetivo da presente pesquisa investigar $\mathrm{o}$ conjunto de conseqüências (físicas, psicológicas, emocionais) dos maus-tratos na criança ou adolescente. Porém, muitos estudos foram feitos nesse sentido e mostram os graves danos provocados pelos maus-tratos. Strassberg, Dodge, Pettit e Bates (1994) comprovaram que crianças que apanham são mais agressivas com seus colegas. Bryant e Range (1995) afirmaram que que as estudantes que sofreram abuso físico e/ou sexual, possuem maior risco de cometer suicídio. Bachar, Canetti, Bonne, DeNour e Shaley (1997) mostraram que a punição física foi associada com altos níveis de sintomas psiquiátricos e com baixo bem-estar geral. E Miller e Knutson (1997) comprovaram a associação entre história infantil punitiva com comportamento anti-social.

O objetivo da presente pesquisa foi o de identificar o perfil e a dinâmica familiar dos envolvidos nas denúncias ocorridas ao programa SOS Criança na cidade de Curitiba. Isto possibilitou um maior esclarecimento acerca do fenômeno e uma discussão acerca das formas de maus-tratos contra crianças e adolescentes. 


\section{Método}

\section{População}

Foi feito um estudo de corte transversal de 400 formulários de registro de dados dos arquivos do SOS Criança de Curitiba. As denúncias eram relativas às crianças e adolescentes de zero a 18 anos que tinham sofrido qualquer tipo de maus-tratos entre os anos de 1995 e 2000.

\section{Material}

Com o instrumento para a coleta de dados, foi elaborado um protocolo para recuperação sistemática e objetiva dos dados constantes em cada prontuário e um espaço para anotações qualitativas particulares de cada caso. Foram analisados a denúncia recebida, o denunciante, o agressor, a verificação ou não da denúncia, direitos feridos, identificação geral da criança, história e constituição familiar.

\section{Procedimento}

Obteve-se permissão da Secretaria Municipal da Criança e da diretoria do SOS Criança, para a realização da pesquisa. Os dados foram coletados in loco. A pesquisa seguiu uma metodologia documental (descritiva e inferencial), sendo realizado um processo de amostragem randômica simples dos prontuários que continham dados dos atendimentos realizados. Foram analisados o tipo de serviço solicitado, os procedimentos de investigação da denúncia e a duração do acompanhamento. Os dados coletados nos prontuários de registro do SOS Criança foram inicialmente transcritos e codificados para o formulário de coleta e, em seguida, digitados em uma base de dados do SPSS para permitir o cruzamento das diferentes variáveis encontradas.

\section{Resultados e Discussão}

A análise dos dados do presente artigo foi realizada apenas com base nas denúncias verificadas $\mathrm{e}$ comprovadas, diferenciando-se de outras pesquisas que geralmente analisam todas as denúncias e não as denúncias de fato comprovadas. Portanto, dos 400 prontuários investigados, 269 (67,3\% do total da amostra) não foram utilizados por não serem o foco deste estudo. Os casos não comprovados foram analisados separadamente. Para todas as provas estatísticas foi adotado o nível de significância $\mathrm{p}<0,05$.

\section{Perfil das vitimas}

Das crianças e adolescentes vítimas de maustratos, $48,5 \%$ são do sexo feminino e $51,5 \%$ do masculino. Quanto à idade: 33,8\% são sujeitos de zero a quatro anos; $30,8 \%$, de cinco a nove anos; $35,4 \%$, de mais de dez anos. Na Tabela 1 pode-se observar a variação da freqüência da idade de acordo com o sexo das vítimas.

Tabela 1 - Apresentação dos dados cruzados entre gênero e idade (em porcentagem)

\begin{tabular}{l|ccc}
\hline & Feminino (\%) & Masculino (\%) & Total (\%) \\
\hline De 0 a 4 anos & 17,7 & 16,2 & 33,9 \\
De 5 a 9 anos & 12,3 & 18,5 & 30,8 \\
Mais de 10 anos & 18,5 & 16,9 & 35,4 \\
Total & 48,5 & 51,5 & 100,0 \\
\hline
\end{tabular}

A Tabela 1 mostra que a distribuição das idades em relação ao gênero se fez de forma bastante homogênea, podendo-se constatar que não houve diferença estatística significativa $\left(\chi^{2}=1,656 ; \mathrm{gl}=2 ; \mathrm{p}=\right.$ $0,437)$. A maior parte das vítimas $(64,6 \%)$ tem até nove anos (tanto meninos quanto meninas). Esse dado coincide com o de Pires (1999), o qual constatou que $55,9 \%$ das vítimas eram crianças de zero a nove anos.

Foram analisados também os tipos de maustratos sofridos pelas vítimas. Verificou-se que a maior parte delas foi agredida fisicamente, como mostra a Figura 1. 


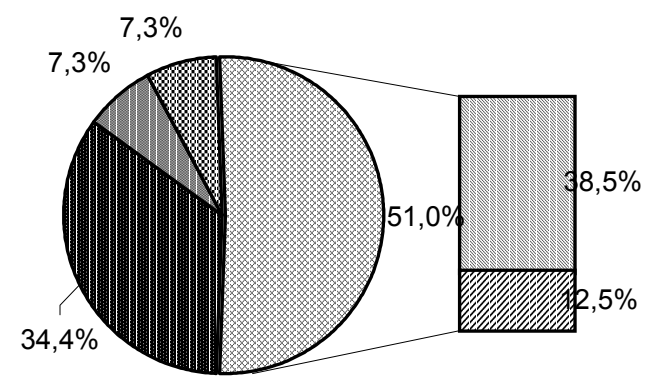

negligência

abandono

abuso sexual

⿴囗十violência física

agressão sem lesão

Figura 1 - Porcentagem dos tipos de maus-tratos sofridos pelas vítimas.

De acordo com a definição de maus-tratos estabelecida nesta pesquisa, estes puderam ser classificados em cinco categorias, visualizadas na Figura 1, possibilitando uma melhor análise dos dados. As agressões físicas somaram um total de 51,0\%, no qual 38,5\% corresponderam à violência física e $12,5 \%$, à agressão sem lesão aparente. Os outros 49,0\% distribuíram-se entre: negligência (34,4\%); abandono (7,3\%); abuso sexual (7,3\%).

Exemplos de casos de agressão física mostraram uma criança com seis anos que teve seus cabelos arrancados, e outra, de nove anos, agredida em seu rosto com um ferro quente, além de ser obrigada a pedir esmolas na rua, e levar comida e dinheiro para casa. Foram encontradas também situações que caracterizam verdadeira tortura, como obrigar uma criança de dois anos a comer as próprias fezes para aprender a utilizar adequadamente o banheiro. Os exemplos de negligência incluem casos como o de uma criança de dois anos que se apresentava em grave estado de saúde, pois indevidamente lhe era administrado remédio para diabetes em sua mamadeira.

É importante alertar que a negligência é também um problema social que tem raízes nas diretrizes políticas do Poder Público e na profunda desigualdade social existente em nosso país. Em muitas famílias de baixa renda, os pais ou responsáveis trabalham o dia todo para sustentar a família. Assim, podem não ter com quem deixar seus filhos, pois o governo não disponibiliza vagas suficientes em creches municipais para atender à demanda da população carente, como indica a mídia impressa paranaense ao informar que 20 mil crianças estão a espera de vagas em Curitiba (Jornal do Estado-PR, 14/11/2001) e 12 mil crianças em Londrina (Folha do Paraná - Cidades, 13/3/2001).

Foi realizada a análise para esclarecer se o gênero estava relacionado com o tipo de maus-tratos sofridos pela vítima. A Figura 2 apresenta a relação de maus-tratos com o gênero.

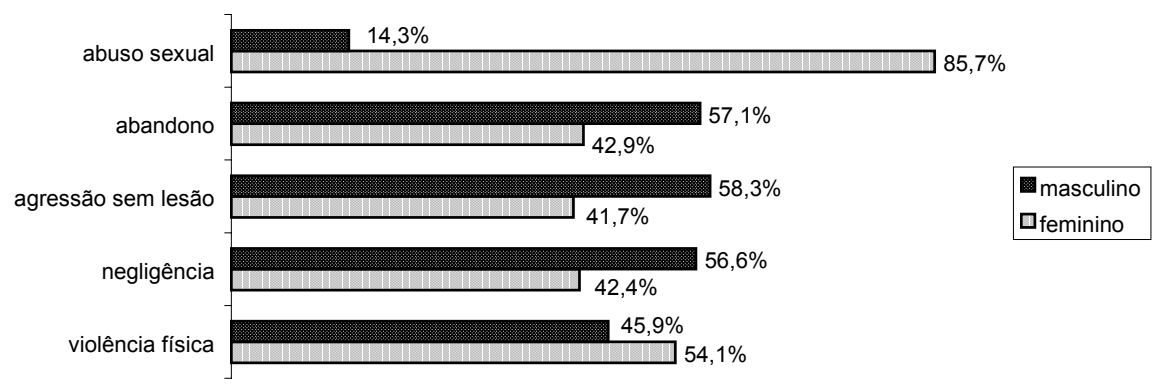

Figura 2 - Percentual dos tipos de maus-tratos por gênero das vítimas.

Apesar de os meninos terem tido uma representação um pouco maior no abandono ( $2=$ 2,016; p > 0,05), na agressão sem lesão aparente ( $2=$ $2,756 ; \mathrm{p}>0,05)$ e na negligência $(2=1,742 ; \mathrm{p}>$ $0,05)$, e as meninas na violência física $(2=0,672 ; \mathrm{p}>$ $0,05)$, essas diferenças não foram significativas. A única diferença estatisticamente significativa foi encontrada entre os gêneros em relação ao abuso sexual ( $2=$ 50,980; $\mathrm{p}<0,05)$, em que a freqüência em meninas foi muito maior.

\section{Sobre os agressores}

Em relação aos autores dos maus-tratos, foram analisados freqüência, sua relação com o tipo de maus- 
tratos e com o motivo declinado pelo agressor. A Figura 3 mostra o percentual dos agressores denunciados ao SOS Criança e cujas denúncias foram verificadas.

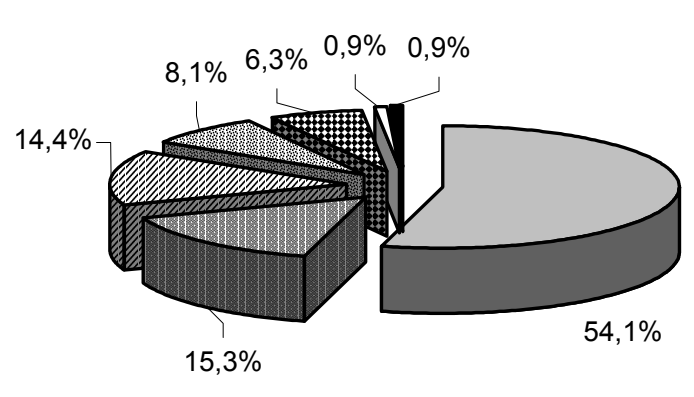

\author{
口Mãe \\ $\square$ Pai \\ 回Pai e mãe \\ 圈Responsável legal \\ 国Outro familiar \\ 口Vizinho
}

Agressor desconhecido

Figura 3: Percentual dos agressores.

Verificou-se que a maioria dos agressores são pessoas que fazem parte do vínculo familiar da vítima. Num total de $98,2 \%$ de agressores, $54,1 \%$ foram mães, $15,3 \%$ pais, $14,4 \%$ pais e mães, $8,1 \%$ responsável legal, e 6,3\% outro familiar. Weber, Viezzer \& Zocche (2001) também encontraram $85,8 \%$ de mães que batem em seus filhos em uma pesquisa realizada com crianças de escolas públicas e particulares. Verifica-se, então, que as crianças estão sendo agredidas mais freqüentemente no ambiente que deveria propiciar proteção e cuidados à criança e ao adolescente: no seu próprio lar. Em quase a totalidade dos casos $(98,2 \%)$ os agressores detinham poder legal e/ou dever de zelar pelo bem-estar da criança/adolescente.

$\mathrm{Na}$ relação entre agressores e os tipos de maustratos aplicados $\left(\chi^{2}=55,897 ; \mathrm{gl}=24 ; \mathrm{p}<0,001\right)$ encontrou-se diferença significativa: a mãe foi a autora na maioria dos casos de negligência (62,5\%); em segundo lugar foram pai e mãe $(25,0 \%)$; depois outros familiares $(9,4 \%)$ e por último somente o pai $(3,1 \%)$. A mãe também foi a principal autora dos casos de violência física $(55,9 \%)$, o pai ficou em segundo lugar $(32,4 \%)$, e os demais (pai e mãe associados, responsável legal, outro familiar, vizinho) distribuíram-se igualmente $(2,9 \%$ cada um). Foram descritos somente os dados de violência e negligência por serem os tipos de agressão mais freqüentes, enquanto os demais tipos de maus-tratos apresentaram uma distribuição mais homogênea entre os agressores.

Como forma de defesa contra as denúncias, os agressores apresentaram vários tipos de alegação na tentativa de justificar seus atos. As alegações podem ser mais bem observadas na Tabela 2 .

Tabela 2 - Apresentação da freqüência (porcentagem) dos tipos de alegação dadas pelo agressor para justificar os maus-tratos

\begin{tabular}{l|c}
\hline Motivo alegado & Percentual \\
\hline Autor negou a denúncia & 20,5 \\
Desobediência ou para corrigir o comportamento da criança & 56,4 \\
Estava fazendo uso de álcool & 12,8 \\
Estava fazendo uso de drogas & 2,6 \\
Estava nervoso & 7,7 \\
Total & 100,0 \\
\hline
\end{tabular}

Em mais da metade dos casos (56,4\%), o agressor alegou estar "educando", "corrigindo o comportamento" da criança ao utilizar a agressão e violência física. Isso vem corroborar o argumento de que as punições físicas aplicadas com intuito de disciplinar são fator de risco para os maus-tratos contra crianças e adolescentes (Hyman, 1997; Whipple e Richey, 1997; Straus, 2001; Azevedo e Guerra, 2001; Azevedo e Guerra, 2002; Weber, Viezzer \& Brandenburg, 2002). Percebe-se claramente a falta de informação e de esclarecimento da população em geral a respeito dos efeitos nocivos da prática punitiva e dos riscos que ela 
traz. Além disso, a violência costuma ser acompanhada de medo, vergonha e/ou raiva e também pode ocorrer uma associação entre a dor que a criança sente quando apanha e o amor em relação aos seus pais, o que ensina a criança a usar o mesmo método em outras situações de sua vida, gerando um círculo vicioso, transmitindo este método coercitivo de geração em geração.

\section{Perfil da familia}

Para que o estudo sobre violência doméstica seja mais completo, é interessante investigar o perfil da família em que as vítimas de maus-tratos estão inseridas. $\mathrm{Na}$ presente pesquisa, a maioria das famílias $(53,5 \%)$ possuía duas pessoas representando os pais, sendo $37,1 \%$ o pai e a mãe, $11,2 \%$ a mãe e o padrasto e $5,2 \%$ o pai e a madrasta. $33,6 \%$ das famílias possuíam apenas um dos pais: em $31,0 \%$ havia somente mães, e em 2,6\% somente pais. No restante das famílias, as crianças não moravam com nenhum dos pais, moravam com responsáveis legais $(7,8 \%)$ ou eram órfãos $(5,2 \%)$.

Tabela 3 - Porcentagens das diferentes composições familiares, organizadas em ordem decrescente

\begin{tabular}{l|c}
\hline Perfil da família & Porcentagem \\
\hline Pai e mãe & $37,1 \%$ \\
Mães sozinhas & $31,0 \%$ \\
Mãe e padrasto & $11,2 \%$ \\
Responsáveis legais & $7,8 \%$ \\
Pai e madrasta & $5,2 \%$ \\
Órfãos & $5,2 \%$ \\
Pais sozinhos & $2,6 \%$ \\
\hline
\end{tabular}

As diferentes constituições familiares demonstraram uma relação significativa com o autor dos maustratos $\left(\chi^{2}=87,037 ; \mathrm{gl}=30 ; \mathrm{p}<0,001\right)$. A maioria absoluta das crianças que moravam com um dos genitores foi agredida por ele. Dos $33,6 \%$ casos em que a família possuía somente o pai ou somente a mãe, em $28,7 \%$ foi esse pai ou essa mãe quem maltratou a criança. Nos casos em que as vítimas moravam com pai e mãe, o autor foi ou a mãe em 39,5\% deles, ou ambos em $34,2 \%$, ou o pai em $26,3 \%$. Sobre as famílias em que apenas um dos pais maltratava o filho, deve-se pensar que seu cônjuge ou está consentindo ou não está ciente do fato. A probabilidade de o próprio cônjuge denunciar pode ser bastante baixa em razão do vínculo afetivo. Isso pode ser percebido na presente pesquisa, já que pais e mães não constam entre os denunciantes (Figura 5).

Como houve relação entre os agressores e a constituição familiar a que pertencem, questionou-se então se os tipos de maus-tratos também variaram entre as diferentes famílias. Para realização dessa análise, os casos em que a criança morava somente com o pai ou somente com a mãe foram agrupados, assim como o foram os casos em que as crianças moravam com pai e madrasta ou mãe e padrasto. Os resultados do cruzamento realizado se encontram na Figura 4. 


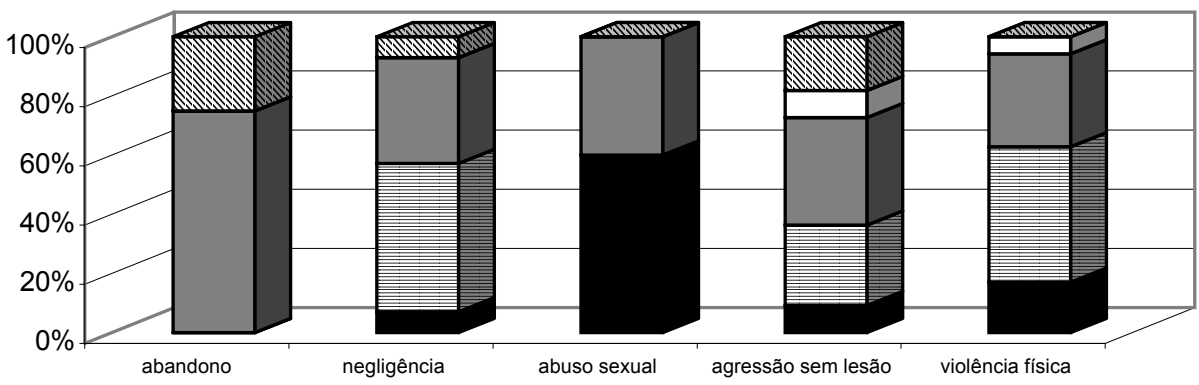

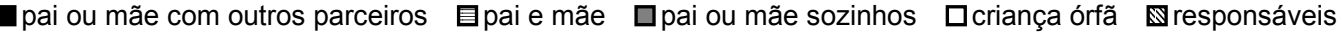

Figura 4 - Tipos de maus-tratos e percentual do perfil das famílias.

A Figura 4 revela as diferenças entre familias monoparentais e completas. A criança foi vítima de maustratos morando somente com o pai ou somente com a mãe em 75,0\% dos casos de abandono, $35,7 \%$ dos de negligência, $40,0 \%$ dos de abuso sexual, $36,4 \%$ dos de agressão sem lesão aparente, $31,4 \%$ dos de violência física. Todos os tipos de maus-tratos tiveram uma certa representação nos casos em que a criança morava com apenas um dos genitores. Os casos das famílias constituídas por pai e mãe estão presentes em $50,0 \%$ das denúncias por negligência, em $27,3 \%$ por agressão sem lesão aparente e $45,7 \%$ por violência física. As famílias com pai ou mãe com outros parceiros tiveram pequena representação nesses três tipos de denúncias $(7,1 \% ; 9,1 \%$ e $17,0 \%$ respectivamente). $\mathrm{O}$ valor mais preocupante é o da freqüência desse tipo de família em casos de abuso sexual: $60,0 \%$, o que pode ser explicado pelo fato de o padrasto ou madrasta terem menor vínculo afetivo com os filhos do(a) esposo(a) e terem maior probabilidade de serem abusadores. Há estudos que mostram estatísticas a respeito de maior violência em relação a crianças perpetrada por padrastos e madrastas do que pelos seus pais biológicos (Ades, 2001; Hrdy, 2001). O problema parece estar na vinculação afetiva.
Não somente a constituição familiar é importante, como também o é a condição socioeconômica da família. Da amostra analisada nesta pesquisa, $44,7 \%$ das vítimas eram de famílias de classe baixa; $37,9 \%$ de classes muito pobres; $14,6 \%$ de classe média baixa; $2,9 \%$ de classe média alta. É chocante a diferença entre a freqüência das classes mais e menos favorecidas: as classes médias, alta e baixa, somam somente $17,5 \%$ e as classes baixa e muito pobre somam 82,5\%. Pinto e Brandão (1999) realizaram um levantamento no Centro de Referência da Criança e do Adolescente de Ribeirão Preto e verificaram que a desestrutura econômica, a miséria e a queda do poder aquisitivo estavam presentes em $90 \%$ dos casos de violência física e psicológica atendidos.

Deve-se, porém, perceber que a ocorrência de maus-tratos não está linearmente relacionada com o nível socioeconômico, pois houve maior freqüência de vítimas em famílias de classe baixa do que em famílias classificadas como muito pobres. O cruzamento entre classes socioeconômicas e tipo de maus-tratos (Tabela 4) foi significativo $\left(\chi^{2}=45,743 ; \mathrm{gl}=12 ; \mathrm{p}<0,001\right)$, mas entre classes socioeconômicas e autor dos maustratos não o foi $\left(\chi^{2}=18,096 ; \mathrm{gl}=18 ; \mathrm{p}=0,449\right)$.

Tabela 4 - Porcentagens das categorias socioeconômicas nos diferentes tipos de maus-tratos

\begin{tabular}{l|ccccc}
\hline Classes & Abandono & Negligência & Abuso Sexual & Agressão sem lesão & Violência Física \\
\hline Média alta & & & & & $9,1 \%$ \\
Média baixa & & $10,7 \%$ & & $70,0 \%$ & $9,1 \%$ \\
Baixa & & $28,6 \%$ & $80,0 \%$ & $30,0 \%$ & $57,6 \%$ \\
Muito pobre & $100 \%$ & $60,7 \%$ & $20,0 \%$ & & $24,2 \%$ \\
TOTAL & $100 \%$ & $100 \%$ & $100 \%$ & $100 \%$ & $100 \%$ \\
\hline
\end{tabular}


Ao analisar esses resultados, deve-se lembrar que se trata de dados de denúncias ao SOS Criança. Os maus-tratos foram mais denunciados nas classes menos favorecidas economicamente, mas é provável que existam casos de abandono, de negligência e de abuso sexual em famílias mais privilegiadas sem que sejam denunciados, uma vez que os lares são mais protegidos de vizinhos - os principais denunciantes. Mesmo assim, compreende-se a razão de o abandono e a negligência serem mais freqüentes nas classes menos privilegiadas ao se observar os dados do IBGE (Instituto Brasileiro de Geografia e Estatística) de 1999: 31\% das famílias brasileiras ganham menos de três salários mínimos por mês, $11,1 \%$ ganham menos de um salário mínimo por mês e 3,5\% das famílias brasileiras não tem renda alguma. Como suprir as necessidades básicas de alimentação, higiene, vestuário, atendimento à saúde, em condições tão precárias? As profundas desigualdades sociais e de distribuição de renda influenciam as condições em que as crianças e adolescentes brasileiros são criados (Guerra, 1998).

Sobre as agressões físicas, deve-se chamar a atenção para sua freqüência na classe muito pobre: não houve denúncias de agressão sem lesão aparente, e a violência física teve menor freqüência que em famílias de classe baixa (um pouco mais privilegiadas). Estes baixos valores encontrados para as famílias muito pobres podem ser explicados com a hipótese de que neste meio socioeconômico, a noção de agressão física seja diferente, por ser mais banalizada. Talvez o senso crítico de que a agressão física contra uma criança seja um crime - e deve ser denunciado - seja mais característico de pessoas de classes um pouco mais favorecidas.

\section{Sobre o denunciante e denúncias não verificadas}

Normalmente os maus-tratos infantis ocorrem dentro de casa e provavelmente poucas pessoas ficam sabendo, em virtude de um sinistro silêncio cultural em torno de assuntos ligados à intimidade de um lar (Guerra, 1998; Veronese, 1998; Azevedo e Guerra, 2001). Mas nos casos aqui pesquisados, alguém se propôs a denunciar, e isso é um fator importante na rede de proteção à criança, tornando pública a violência. A Figura 5 mostra a distribuição percentual das pessoas que fizeram a denúncia ao SOS Criança.

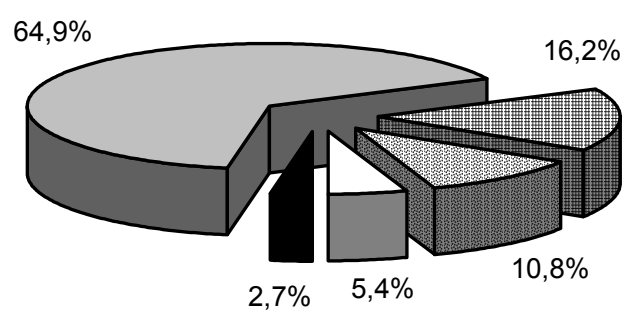

$\square$ Vizinhos

圈Outros familiares

畻Polícia

$\square$ A própria vítima

Conselho Tutelar

Figura 5 - Percentual dos denunciantes com denúncias verificadas.

A Figura 5 mostra que é bastante significativo o envolvimento de vizinhos $(64,9 \%)$ nas denúncias ao SOS Criança, mostrando a relevância do papel da comunidade nas situações de violência contra a criança. Em segundo lugar, estão os outros familiares $(16,2 \%)$, pois estes, muitas vezes, presenciam cenas de maus-tratos intrafamiliares.

Ao cruzar os dados entre denunciante e tipo de maus-tratos $\left(\chi^{2}=40,161 ; \mathrm{gl}=16 ; \mathrm{p}=0,001\right)$, verificouse diferença significativa, ou seja, os vizinhos denunciaram, na maioria dos casos, tanto violência $(42,1 \%)$ quanto negligência $(42,1 \%)$, enquanto os outros tipos de maus-tratos foram bem menos denunciados por vizinhos. No que se refere às denúncias realizadas por familiares, $66,7 \%$ destes denunciaram violência e os outros 33,3\% denunciaram negligência, ou seja, a família extensa está mais atenta a casos de agressão do que de negligência.

Quanto às denúncias não verificadas, constatouse um número muito grande de casos $(67,3 \%$ da amostra total), sendo $51,6 \%$ denúncias de violência, $25,1 \%$ de negligência, $11,9 \%$ de agressão física sem lesão aparente, $8,2 \%$ de abuso sexual e $3,2 \%$ de abandono. Ao se verificar quais foram os denunciantes desses casos (não verificados), constatou-se que $68,2 \%$ foram vizinhos, e $14,8 \%$ outros familiares (os outros denunciantes apresentaram percentual muito baixo). Isso pode significar que é muito difícil comprovar o que acontece de fato dentro de uma casa, ou então que existe um 
despreparo enfrentado por muitos profissionais para detectar evidências desse tipo de agressão. Os vizinhos podem estar sabendo dos maus-tratos, por ouvirem gritos, choros ou perceberem a criança trancada dentro de casa, mas com a chegada de técnicos, a família pode camuflar a realidade.

$\mathrm{Na}$ maioria dos casos de denúncia não comprovada, verificou-se a violação de outros direitos: em $30,1 \%$ destes casos feriu-se o direito à liberdade, ao respeito e à dignidade; em 25,3\% feriu-se o direito à convivência familiar e comunitária; em 3,0\% feriu-se o direito à vida e à saúde; em 1,1\% feriu-se o direito à educação, cultura, esporte e lazer; e em $0,7 \%$ feriu-se o direito à profissionalização e proteção no trabalho. Em $37,5 \%$ destes casos de denúncia não verificada, a situação não envolveu violação de direitos e em 2,2\% mais de um direito foi ferido.

O fato de grande parte dos casos $(37,5 \%)$ não terem sido enquadrados em violação de direitos, pode significar que, mesmo que tenha ocorrido algum tipo de maus-tratos, por lei não foi considerado como tal. Isso pode ser duplamente perigoso, uma vez que algumas leis podem estar acobertando atitudes nocivas dos pais em relação aos filhos, considerando-as corretas e deixando-as impunes. De acordo com o alto percentual da violação de outros direitos que não o denunciado (total de 60,2\%), pode-se concluir que muitos dos denunciantes percebem "algo de errado" e sem saber muito bem o que está acontecendo denunciam, ocorrendo então a verificação de outros direitos feridos que não aquele relatado na denúncia principal.

\section{Conclusões}

O que é maltratar uma criança? Machado (1996) questiona se a diferença está nos atos (e se está, qual é a medida objetiva que permite diferenciar a punição física dos maus-tratos) ou nas intenções subjacentes (e assim poderia um mesmo ato ser punição adequada ou maltrato psicológico, dependendo da intenção que lhe subjaz). De um jeito ou de outro, o que está em jogo é o desrespeito à criança e a violação dos direitos de crescer com amor, diálogo, paciência e de se desenvolver em sua plenitude. Todo tipo de maus-tratos é injustificável, tanto do ponto de vista moral, social, humano, quanto psicológico e científico.

A presente pesquisa revelou que, dentre os maus-tratos denunciados ao SOS Criança, houve predomínio da violência física, seguido pela negligência. Os vizinhos foram os que mais denunciaram, e as mães foram as principais agressoras. Também foi explorado o perfil das famílias que maltratam; com isso é possível delinear novos estudos sobre fatores de risco para os maus-tratos e programas de prevenção. Os dados revelaram indícios de alguns dos fatores de risco para os maus-tratos contra a criança: família monoparental e pobreza. Outros fatores de risco (Machado, 1996; Azevedo e Guerra, 2002) são o desemprego, a baixa escolaridade, a agressão sofrida pelos pais na infância (que o faz acreditar que a violência é uma forma adequada para educar). Pode-se perceber que grande parte dos fatores de risco refere-se a aspectos sociais, o que implica um problema muito maior, não se restringindo às paredes de uma casa. É necessário ainda que haja capacitação permanente de pessoal e integração do Programa SOS Criança à rede de serviços sociais e de saúde.

Não apenas o baixo nível socioeconômico e profissional das famílias denunciadas é determinante dos maus-tratos, mas a sua associação com a menor probabilidade de acesso a estruturas de redes de suporte social, com a ignorância acerca de estratégias educativas eficazes e com a perpetuação do modelo de que é preciso garantir a todo custo a autoridade parental. Toda essa combinação pode ser desencadeadora de violência.

Queimar a criança com ferro de passar roupa ou com cigarro, jogar o bebê na parede por não suportar o seu choro ou cortar os lábios de uma criança que fala palavrão tem múltiplos determinantes na história de vida de cada família. Alguns deles estão associados a dificuldades na identificação e decodificação dos sinais emocionais emitidos pelas crianças, ignorância das fases de desenvolvimento, interpretação inadequada. Por exemplo, o choro do bebê ser interpretado como sinal de uma intencionalidade manipulativa ou de hostilidade, crédito na disciplina coercitiva como mantenedora do status hierárquico da parentalidade (Kropp \& Haynes, 1987; Machado, 1996; Weber, 2001).

Em muitos casos, a violência pode ser entendida pelas famílias abusadoras como uma estratégia para a resolução de problemas. Freqüentemente situações de agressão conjugal (violência doméstica contra a mulher) estão associadas aos maus-tratos contra a criança (Browne \& Hamilton, 1999; Kerig \& Fedorowicz, 1999; Machado, 1996; McCaghy, 1985; Shipman, Rossman \& West, 1999).

A análise dos dados coletados demonstrou que a situação é de urgência. Torna-se necessária a mobilização de todos para que as estatísticas deixem de ser apenas um vergonhoso retrato das relações adultocriança, e tornem-se verdadeiros motivos de preocupação social. O problema dos maus-tratos infantis 
merece mais atenção, por parte de pesquisadores e por parte da sociedade como um todo, pois traz muitos danos ao desenvolvimento da criança, tais como: baixa auto-estima, dificuldade em estabelecer vínculos afetivos, isolamento, agressividade, falta de confiança e segurança, dor emocional e ressentimento contra a vida. Além do mais, a criança aprende que o poder é sempre do mais forte e, portanto, que a violência é algo bom, permitido e aceitável para disciplinar ou expressar raiva (Bachar, Canetti, Bonne, DeNour \& Shaley, 1997; Bryant e Range, 1995; Miller e Knutson, 1997; Straus, 1994; Strassberg, Dodge, Pettit \& Bates, 1994; Weber, 2001; Whipple \& Richey, 1997). A violência perpetua um círculo vicioso no qual há grande probabilidade de o agredido tornar-se $\mathrm{o}$ agressor. E não é esse o mundo que se quer construir.

\section{Referências}

Ades, C. (2001). Bater nos filhos: mania de homens ou de animais? Filhotes agredidos. Em M. A. Azevedo \& V. N. A. Guerra. Mania de bater. São Paulo: Iglu.

Alberton, M. S. (1999). O papel dos Conselhos Tutelares. Em Amencar (Org.). Violência Doméstica. Porto Alegre: Amencar, p. 23-31.

Ariès, P. (1986). História social da criança e da família. Rio de Janeiro: Guanabara.

Azevedo, M. A. \& Guerra, V. N. A. (2001). Mania de bater. São Paulo: Iglu.

Azevedo, M. A. \& Guerra, V. N. A. (2002). Palmada já era. São Paulo: M. A. Azevedo \& V. N. A. Guerra.

Bachar, E., Canetti, L., Bonne, O., DeNour, A. K. \& Shaley, A. Y. (1997). Physical punishment and signs of mental distress in normal adolescents. Adolescence, 32, 945-958.

Badinter, E. (1985). Um amor conquistado. Rio de Janeiro: Nova Fronteira.

Brasil. (1990). Estatuto da Criança e do Adolescente. Lei no 8.069, de 13/7/1990.

Browne, K. D. \& Hamilton, C. E. (1999). Police recognition of links between spouse abuse and child abuse. Child Maltreatment, 4(2), 136-147.

Bryant, S. L., Range, L. M. (1995). Suicidality in college women who were sexually and physically abused and physically punished by parents. Violence and Victims, 10(3), 195-201.

Caminha, R. M. A. (1999). Violência e seus danos à criança e ao adolescente. Em Amencar (Org.). Violência Doméstica. Porto Alegre: Amencar. p. 43-60.
Gallardo, J. A. (1988). Malos tratos a los ninõs. Madrid: Narcea.

Guerra, V. N. A. (1994). Violência física doméstica contra crianças e adolescentes: os difíceis caminhos do conhecimento científico. Temas em Psicologia, 3, 137-153.

Guerra, V. N. A. (1998). Violência de pais contra filhos: a tragédia revisitada. São Paulo: Cortez.

Hrdy, S. B. (2001). Mãe Natureza. Rio de Janeiro: Campus.

Hyman, I. A. (1997). The case against spanking. San Francisco: Jossey-Bass Publishers.

Kaplan, S. J. (1999). Child and adolescent abuse and neglect research: a review of the past 10 years. Part I: Physical and Emotional Abuse and Neglect. Journal of the American Academy of Child and Adolescent Psychiatry, 38, 1214-1222.

Kerig, P. K. \& Fedorowicz, A. E. (1999). Assessing maltreatment of children of battered women: methodological and ethical considerations. Child Maltreatment, 4(2), 103-115.

Kropp, J. \& Haynes, O. (1987). Abusive and noabusive mother's ability to identify general and specific emotion signals of infants. Child Development, 58, 187-190.

Machado, C. (1996). Maus-tratos de menores, vitimização e poder: proposta de um modelo integrado de análise. Psicologia: Teoria, Investigação $e$ Prática, 1(1), 133-147.

McCaghy, C. (1985). Deviant behavior. New York: Maxmillian Publishing Co.

Miller, K. S. \& Knutson, J. F. (1997). Reports of severe physical punishment and exposure to animal cruelty by inmates convicted of felonies and by university students. Child Abuse and Neglect, 21(1), 59-82.

Newell, P. (1989). Children are people too. The case against physical punishment. Londres: Bedford Square Press.

Oliveira, M. S. \& Flores, R. Z. (1999). Violência contra crianças e adolescentes na Grande Porto Alegre Parte A: apenas boas intenções não bastam. Em Amencar (Org.). Violência Doméstica. Porto Alegre: Amencar, p. 71-86.

Pinto, M. P. P. \& Brandão, R. (1999). Violência doméstica contra crianças e adolescentes: um fenômeno multicausal? Em GAPEFAM (Org.). Livro de Resumos do Congresso Internacional Familia e Violência. Florianópolis: GAPEFAM, p. 174. 
Pires, J. M. A. (1999). Violência na Infância - aspectos clínicos. Em Amencar (Org.). Violência Doméstica. Porto Alegre: Amencar, p. 61-70.

Roig, A. M. \& Ochotorena, J. P. (1993). Maltrato y abandono en la infancia. Barcelona: Martínez Roca.

Shipman, K. L., Rossman, B. B. R. \& West, J. C. (1999). Co-ocurrence of spousal violence and child abuse: conceptual implications. Child Maltreatment, 4(2), 93102.

Sibila, P. L. (2001). Visión histórica del maltrato infantil. Obtido do word wide web em 10 de setembro de 2001 http://slaq.prw.net/abusos/vision.htm .

Strassberg, Z., Dodge, K. A, Pettit, G. S. \& Bates, J. E. (1994). Spanking in the home and children's subsequent aggression toward kindergarten peers. Development and Psychopathology, 6, 445-461.

Straus, M. A. (1994). Beating the devil out of them. Corporal punishment in American Families. New York: Lexington Books.
Straus, M. A. (2001). Corporal punishment and primary prevention of physical abuse. Child Abuse and Neglect 24, 1109-1114.

Veronese, J. R. P. (1998). Entre violentados e violentadores. São Paulo: Cidade Nova.

Weber, L. N. D. (2001). Quem ensina a violência? Conjuntura Social, 6, 38-43.

Weber, L. N. D., Viezzer, A. P. \& Zocche, C. (2001). Educação e/ou violência contra a criança? Em Sociedade Brasileira de psicoterapia e Medicina Comportamental (Org.). Caderno de Resumos do X Encontro Brasileiro de Psicoterapia e Medicina Comportamental. Campinas: ABMPC, p. 194-195.

Weber, L. N. D., Viezzer, A. P. \& Brandenburg, O. J. (2002). O uso de palmadas e surras como prática educativa. (artigo submetido a periódico científico).

Whipple, E. E. \& Richey, C. A. (1997). Crossing the line from physical discipline to child abuse: how much is too much? Child Abuse and Neglect, 21, 431-444.

Sobre os autores:

Lidia Natalia Dobrianskyj Weber é psicóloga e especialista em Antropologia Filosófica pela UFPR, mestre e doutora em Psicologia Experimental pela USP, professora da graduação e do mestrado em Psicologia da Infância e da Adolescência e coordenadora do Projeto Criança: desenvolvimento, educação e cidadania da UFPR, com trabalhos em pesquisa e extensão relativos aos estilos parentais.

Ana Paula Viezzer é aluna do 6o período do curso de Psicologia da Universidade Federal do Paraná. Bolsista do PIBIC/CNPq, realiza pesquisa há um ano e sete meses com o tema de estilos e práticas educativas parentais. Além de Iniciação Científica, também faz parte do trabalho de extensão realizando palestras e orientação para pais.

Olivia Justen Brandenburg é aluna do 6o período do curso de Psicologia da Universidade Federal do Paraná. Bolsista do PIBIC/CNPq, realiza pesquisa há um ano e três meses com o tema de estilos e práticas educativas parentais. Além de Iniciação Científica, também faz parte do trabalho de extensão realizando palestras e orientação para pais.

Claudia Regina Endo Zocche atualmente é aluna do curso de Psicologia da Universidade Estadual de Londrina e durante a realização desta pesquisa era aluna do curso de Psicologia da Universidade Federal do Paraná e bolsista de Extensão do Projeto Criança: desenvolvimento, educação e cidadania. 
